$\left.\begin{array}{l}\text { Sournals } \\ \text { INTERNATIONAL JOURNAL OF } \\ \text { ORGANIZATIONAL LEADERSHIP }\end{array}\right) \begin{gathered}\text { INDUSTRIAL } \\ \text { MANAGEMENT } \\ \text { INSTITUTE }\end{gathered}$

\title{
The impact of team-based learning on knowledge development
}

\author{
Aghdas Nikooravesh ${ }^{1}$, Ashrafolsadat Parpoochi ${ }^{2 *}$, Amir Hossein Mohammad Davoudi ${ }^{3}$ \\ ${ }^{1}$ Faculty of Humanities and Social Sciences, Department of Educational Administration, Garmsar Branch, \\ Islamic Azad University, Garmsar, Iran \\ ${ }^{2,3}$ Faculty of Humanities and Social Sciences, Department of Educational Administration, Saveh Branch, \\ Islamic Azad University, Saveh, Iran
}

\begin{abstract}
Keywords:

Team-based Learning, Knowledge Management, Education

Received

01 December 2015

Received in revised form 25 April 2016

Accepted

28 April 2016

Correspondence:

Learning is the most important component of education. However, experts must try to improve the quality and methods of ideal learning through implementing new methods and spending educational cost to improve internal efficiency and productivity. One of the most common methods is the team-based learning. Team-based learning is considered as a strong instructional strategy to benefit from using small groups and people participating in learning and using others' experiences to attract, develop, and manage the knowledge. This learning method is based on group activities to create and develop active and more effective learning. Effective learning leads to create the knowledge, increase the ability and awareness of teachers and students, and improve the education. The literature review also mentions the concepts which have effective role on team-based learning, creating, and developing the knowledge.
\end{abstract}

af.parpoochi@gmail.com

(C)AIMI Journals

\section{Introduction}

Strange developments in current world resulted from human learning. Our nature was constantly changing and therefore human constantly tried to learn and to broaden his/her experiences to coordinate with changes and transformations or cope with them. Human reached intellectual promotion through learning, promoting virtue, and helping thought promotion. Learning is defined as acquiring, understanding, and dominating knowledge through experience or study. Theoreticians defined the concept of learning differently, but Hilgard and 
Marquis (1940) have defined this concept comprehensively. Learning refers relatively to the stable changes in behaviour or behaviour potential of learners as a result of acquiring experience (Pashler, McDaniel, Rohrer, \& Bjork, 2008). In fact, being the principle of curriculum in different institutions, universities, factories, and workshops has been one of the most extended human activities (Parsa, 1995). Learning is not a unilateral process of learning which has been transmitted from people to groups and organizations and institutional learning influences people or groups. However, sharing idea and developing a common meaning have been the basic mechanism underlying learning. Acquiring, sharing knowledge, and profiting from it have been three important processes which help organizational learning start (Chan, 2003). Meanwhile, many thinkers including Senge (1990) emphasized the importance of teambased learning to acquire learning in organizational levels and considered team-based learning approach as a method or bridge to acquire organizational learning. Undoubtedly, using new methods of learning have helped learners to improve their learning trends and share their knowledge and experiences. If learners profited from cooperative learning processes in their learning, they would share their implicit knowledge with their teammates and develop it additionally to speed up the teaching and learning process. Today, team-based learning has been one of the newest learning methods. This method meant that teams as an entity has been able to think create, and learn. It is the process in which enhance the members' abilities who have the same tendency so that its results would be what people want. Teams learn from their experiences how to learn better and reach new approaches as well as extending their knowledge around the organization. In fact, if team didn't learn, organization would not learn; therefore, team-based learning approach is inevitable in organizations (Yaghoubi, Agharahimi, Daryabeygi, \& Javadi, 2012).

\section{Team-based Learning}

The most well-known use of team-based learning is found in the book of Pieter Singe (2001). Senge stated that team-based learning is vital, because effective team-based training reflects general principles of learning theory in modern organizations. Team-based learning does not mean that the members constantly develop their own personal and learning skills. In fact, it has been considered as a group system by which team members promote their own swarm intelligence (collective behaviour). Team-based learning as an educational strategy has been organized on the basis of team activities. Effective learning can promote through interaction within small groups in one semester (Michelson et al., 2002). Being suitable for team-based learning, educational units included considerable amount of information which students must comprehend. This information includes solving problem, answering the questions, and solving problems by team activities. Also, this learning approach has been suitable for greater educational units (Sibley \& Par melee, 2008); therefore, team-based learning has been considered as an alternative to lecture in large classes. Most of learning experiences refer to the activities which were done in the form of team activities during interactions in the class (Michelson et al., 2002). The materials being presented is broken down into educational units could be divided into smaller parts and students could be divided into teams. Table 1 presents 
the guidance of Michelson for the stages of team-based learning activities in each unit (Gomez, Wu, \& Passerini, 2010).

Table1

Stages of Team-Based Learning in Each Unit

Team-Based Learning Stages in Each Unit

Individual Preparation All needed materials were determined and students obtained them during first meeting. Students did determined materials.

Individual and Team

Readiness Assessment

Application Activity

End of Module Test
Testing the individual readiness assessment was done for each student. After assuring this test (IRAT), it was used for each team (TRAT).

Students have done team activates, have discussed issues, and have begun to rotary exchange information so that all members of team have participated in the exchange. Students have participated in assessing other teams and presented feedback. Participation in teams has provided this opportunity for teachers to present issues supporting class

Final assessment has been done to prove that materials of each unit have been studied completely before transferring to next unit

In team-based learning, one of the especially educational tools is based on participatory learning, active groups, and other active learning strategies in which learning was followed by special and predetermined sequence. Before using team-based learning, the first step was that teachers know the main and essential principles and ideal sequence of events. Teachers did not reach desired purposes of team-based learning unless they could perform its four main principles (Mousavi \& Alavi-Basir, 2014). Team-based learning has been able to create new structures in education. Generally, this type of learning has been considered as a new ability in education that special abilities and high performance learning teams are used by small groups and the structure of each period to develop team.

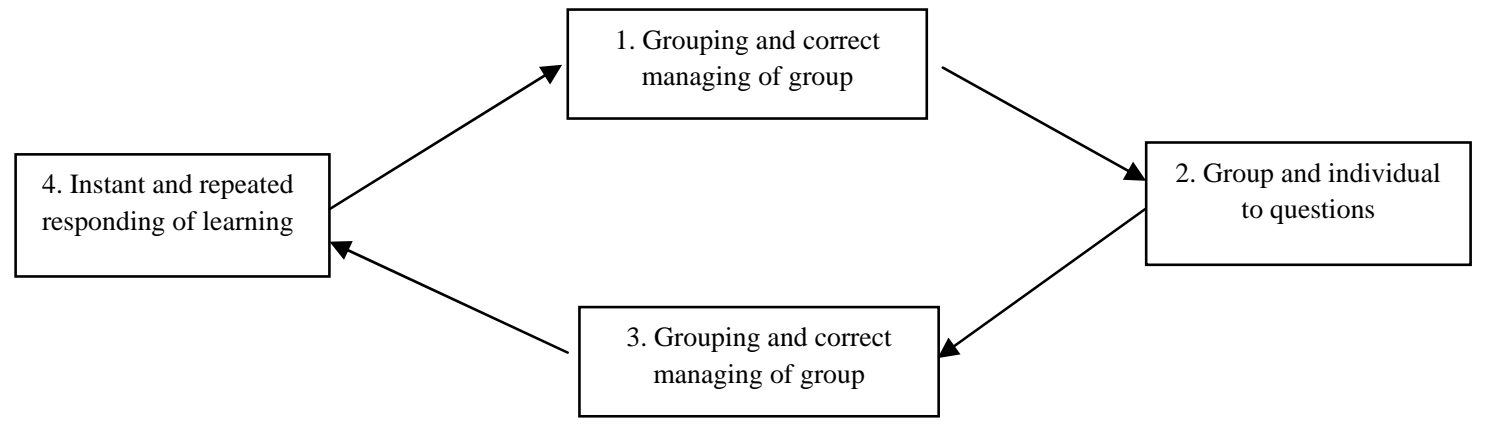

Figure1.The main principles in team-based learning

Such teams tend to have two characteristics which present the main advantages of an ideal educational condition. As a member of team, each student has the ability to reach high- level learning and learning teams have the ability to solve the problems that the most talented members cannot solve them lonely. In other words, the students do not need that the talented people do extraordinary activities in this method. Such teams help each member to understand the educational topics better and solve the challenging issues or complex problems that the talented students of the class are not able to solve them lonely (Michelson et al., 2002). Pulaski county 
special school district considered team-based learning as a method to convert individual learning into organizational knowledge, so that it is usable and accessible by all people. Senge (1990) defined team-based learning as a process in which the members of successful teams all head in the same direction and people have accepted its results. In team-based learning, people have learnt how they share their experiences, learn more, and reach new approaches to spread their knowledge throughout the organization. Therefore, as an effective factor to reach present knowledge in the organizations and change implicit knowledge into the explicit one, it was considered as a valuable approach to reach given purposes in the organizations and educational environments.

\section{Knowledge Management}

So far, the study of developing knowledge management systems has shown that human thought has changed typically. One day, money, wealth, and properties were considered as a type of power, but today having new thought and using it correctly has been considered as a power. In the past, output and quantity were important factors, but today human sources inside the group, managers or teachers in educational organizations, and learners' learning qualities are important factors. Using managerial tools and new technologies are considered as the main conditions of organizational success including educational institutions in the world in which competition among people and organizations are considered very close. Today, not only organizational development depends on having knowledge and managing it properly, but also social survival is based on using new knowledge effectively. Since, knowledge and information are the most important principles for productivity, economic competition, and development and human sources are considered as the most important tools to reach purposes and political and economic goals. Governments usually identify the priorities of human resource training and determine teachers as the most important people because realization of all nations' purposes and wishes depends on the teachers' efforts and nations' improvement is not achieved without teachers' active cooperation and participation.

\section{Knowledge Hierarchy}

In the field of knowledge management, Russell Ackoff (1989) is the first person who has invented DIKW hierarchy. In 1989, he explained hierarchy of philosophical data without mentioning source for it. Besides, this hierarchy has shown that each of them affected others and even changed them into others. Figure 2 shows that knowledge hierarchy has been shown as a knowledge pyramid.

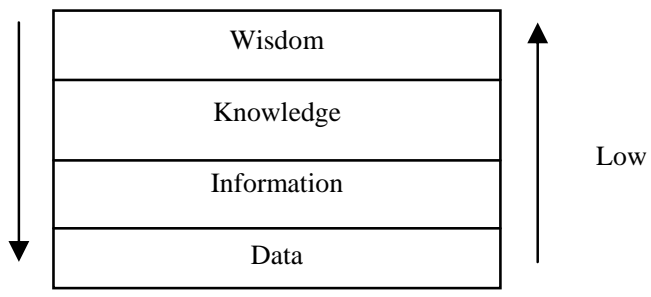

Figure 2. Knowledge pyramid 
Data which is considered as a vital source obtained through changing the raw data into the meaningful information. Raw data has virtual reality and change into information when it has been organized. Data has been a reality of the situation or a case of special issue without communicating with other things; in other words, it is raw material or main element of making decision. Information is defined as data that has meaning and purpose. Information creates data and then affects recipients' insight and attitude. The processing information is effective to respond "what", "where", and "when" questions (Sohrabi \& Darami, 2010). According to Davenport and Purosak (1998), knowledge is considered as a changing combination of information, experience, values, and people's mental and environmental backgrounds. Knowledge affects how the learner perceives new information is created by combining different datum and gives the scholars the ability of collection and evaluation (Hassanzade, 2007). In organizations, knowledge not only was included in files or documents, but also was placed in daily programs, processes, actions, and norms of the organizations. On the contrary, information is always included in human index. Books contain information, but when a person borrows and uses this information, it changes into the personnel knowledge (Sohrabi \& Darami, 2010). Knowledge is considered as an intangible and subjective property and is based on several factors including culture, opinions, values, intuitions, and motivation. Knowledge would be considered as set of people's thoughts which obtain through analysing, understanding, and memorizing information (Mousavi \& Alavi, 2014).

Wisdom is the process of making the impossible possible. However, it may be accompanied by judgement and required previously mentioned levels, especially given types of human programming. Wisdom is considered as the basis for the philosophical investigation.

The concept of truth is more complex than wisdom, because the perceived social phenomenon depends on viewers' attitudes, beliefs, and values. There is not independent observation from viewers' point of view, because implicit views and concepts of our mind toward the world will affect on our observations. The mentioned concepts have been distinguished better by precision in defining each level of knowledge hierarchy and their relation with learning processes and outcomes. Table 2 shows the difference among data, information, knowledge, and wisdom.

Table 2

The Difference between Data, Information, Knowledge, \& Wisdom

\begin{tabular}{l|ccc}
\hline Level & \multicolumn{1}{c}{ Definition } & Learning Process & Outcome \\
\hline Data & Pure Data & Gathering Realities & Memory Storage ( Data Bank) \\
\hline Information & Meaningful and Useful Data & Being Useful in Forming & Understanding (Information Bank) \\
\hline Knowledge & Clear Understanding of Information & Analysis in Combination & Understanding (Knowledge Bank) \\
\hline Wisdom & $\begin{array}{c}\text { Using Knowledge to Determine } \\
\text { Purposes and Achieve them }\end{array}$ & $\begin{array}{c}\text { Knowing Judgements and Doing } \\
\text { Suitable Actions }\end{array}$ & Better Life/Success (Wisdom Bank) \\
\hline
\end{tabular}

\section{Knowledge Types}

Knowledge was divided into two sections including individual and organizational. Individual knowledge is a kind of knowledge that has been formed and remained in people's mind. On the other hand, organizational knowledge is created through communications among technologies, 
techniques, and people. Organizational knowledge can be classified into two categories, namely explicit and implicit (Yaghoubi et al., 2011). Nonaka and Takeuchi (1995) considered explicit knowledge as one which can be coded and therefore it has simply been sent, transferred, preceded, and stored in data bases. Factors such as employees' achievements and their knowledge can maintain and form formal knowledge's reports, files, plans, programs, and records. Knowledge organizations simply gather and maintain the formal knowledge and trust on it as organizational memory. In contrast, implicit knowledge is personal which has been placed in human's mind and accompanied him in his activities (Yaghoubi et al., 2011) and it formalizes with difficulty. Such knowledge obtained through experience, observation, and imitation. It is resulted from actions, methods, commitments, values, and people's feelings which cannot be coded and sent by a language. The importance of implicit knowledge was firstly confirmed by Pelni (1948). This knowledge is obtained through experience and practical learning and is not coded; in other words, it refers to the organizations' unwritten knowledge which determines the amount of employees' experience and skills. Implicit and explicit knowledge are considered as complementary concepts and both of them are necessary in forming knowledge. However, whatever we have called knowledge results from an interaction between the implicit and explicit knowledge not one of them alone.

\section{Knowledge Managements Definition}

Knowledge management is not considered as a new concept in human history and it has accompanied humans at the different ages to satisfy the societies' needs. The concept of knowledge management has been generalized in recent years. Although, it has been widely used in many different organizations and institutions, it is a notoriously difficult term to define. Baier (1986) believed that acquiring organizational purpose through creating motivation, facilitating users' knowledge creation and transfer, and using scientific sources, present experiences, skills, and present cultures formed the knowledge. Sabin, Larson, and Nellen (2000) believed that the knowledge sharing environment should be managed not knowledge itself. Knowledge management is the art of evaluating intangible activities of an organization. Several dimensions of knowledge management are presented in Figure 3. 


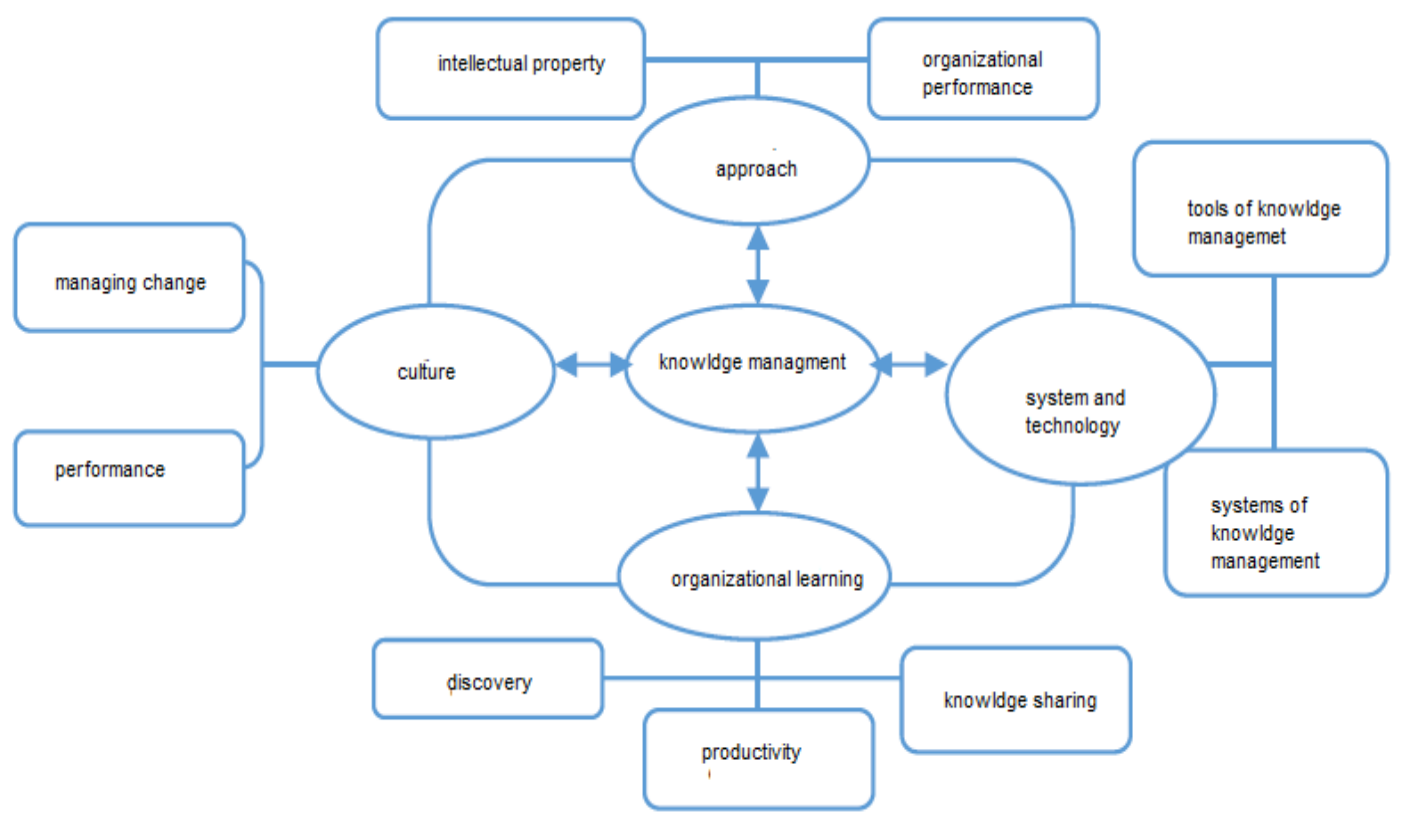

Figure3. Dimensions of knowledge management

Figure 3 presented concepts and definitions about knowledge management, implicit and explicit knowledge, and principles of knowledge management. Nevertheless, the mentioned principles would be summarized according to two most famous knowledgeable individuals. Davenport and Prusak (1998b) have proposed the key knowledge management principles and concepts in their book which is called working knowledge. They stated that knowledge results from people's though and placed in their thoughts, sharing knowledge needs confidence, technology allows new knowledge behaviour, knowledge sharing should be encouraged and rewarded, support of managers and sources are considered necessary, knowledge creates identity for people and encourage them which leads to unexpectedly development of knowledge (Jafari Moghaddam, 2009). Davenport and Prusak (1998a) mentioned the effective knowledge transfer principles including making communication confidence through face to face visits, creating common principles through teaching, discussing, publishing, team works, and work flow; predicting the times and places of transferring knowledge, exhibitions, conversation rooms, and reports of conferences; evaluating performances according to the knowledge sharing and creating, training employees to be adaptable through determining time for their learning and introducing new thoughts to them, persuading knowledge nonhierarchical attitude due to the importance of thought quality, rewarding those who are accepting the spaces of making creativity and cooperation of people.

Qelichkhani (2009) believed that knowledge management has many advantages for people, communities, and organizations. In individual level, it helps people to do their duties better and save time during decision making. It provides a sense of collective commitment in the organization and helps people to update themselves and it also offers opportunities for participating people.

From the perspective of communities of practice, knowledge management has developed and created professional skills and behaviours for members through creating common language so 
that members support each other more. In organizational level, knowledge management helps the strategies to be performed and issues to be solved. Also, it leads to profit from more ideas, increase innovative opportunities, and help organisations by making organizational memory so that organizations place in a better competitive condition.

According to Drucker (1984), knowledge is considered as the only source of stable competitive advantage in the future and there is evidence that as it uses more it increases more. However, it is considered as a vital factor in the growth and success of each effort. Knowledge management refers to the systematic efforts which perform in the organizations to find, organize, access intangible properties of organization, strengthen the continuous learning, and share knowledge (Salarzehi, Moradzade, \& Arab, 2012). It furthermore helps the organizations to identify, choose, organize and publish important information and skills considering organizational memory. This issue has enabled organizational management to solve learning issue, plan strategically, and make dynamic decisions effectively.

In some organizations, knowledge sharing becomes a natural issue and power which dominates in other organizations. Knowledge is often considered as a source of power, influence base, and sponsor of continuing job and individuals do not tend to share it with others. Organizational support of information sharing and knowledge creating among employees lead to effective define of processes. Lee, Huynh, Chi-Wai, and Pi (2000) defined knowledge sharing as set of activities of transferring or disseminating knowledge from person, group, or organization to another. Garfield (2006) introduced knowledge hoarding as lack of knowledge sharing behaviours. Davnport and Prusak (1998a) and Fulk, Heino, Flanagin, Monge, and Bar (2004) believed that knowledge is a social activity that occurs in the systems where knowledge is considered as the primary source of value. Knowledge sharing is one of the knowledge management stages and is considered as its most important part. Finally, it attends to how a person would obtain correct information.

\section{Knowledge Management in Schools}

Today, survive and development of organizations heavily depends on the correct knowledge and its management especially social survive which is based on using new and effective knowledge. To make knowledge-based society, education is considered as the main base. Teachers who have executive functions in our education influence on direct education and society. Teachers have a key role in transferring knowledge and behaviour; therefore, working conditions in which teachers must be trained should be changed in a way that teachers change to the educators not the mere experts in transferring curriculum contents (Yousefi \& Gholami, 2006). Teachers are considered as the knowledge workers who present and enhance professional knowledge for class practice. According to Sallis and Jones (2002), teaching means producing and using knowledge. Teachers have not to teach their students but they have to share knowledge with them. A teacher acquired knowledge through experience but his or her expertise accompanied him/her after leaving school. Knowledge management is an important concept in schools and executing knowledge management system in schools like other organizations is not an easy task. In knowledge management, teachers usually have unused tacit knowledge and their actual skills are more than observable knowledge. Therefore, it 
becomes very difficult to determine unused knowledge and its properties. Chi-Hong (2010) believed that there have been three fold reasons to adopt knowledge management in teaching. First, maintaining the teaching expertise of experienced teachers and sharing it with other ones. Second, increasing instructional effectiveness and learning performance of school, and creating competition among schools for teachers which improve the students' learning outcomes. Third, knowledge management supports developing knowledge and increases learning culture in organizations, Electronic learning, and intellectual and legal properties of school.

Knowledge management aims at recognizing knowledge and making these resources accessible. Since, in knowledge age, we try to support and use knowledge management in education, it will be necessary to consider knowledge of human presented in education. Knowledge management is the art of performing knowledge actions which has many advantages including developing intelligence of organizing students, enabling students to adapt themselves with environmental and social conditions, giving students new information, preparing school authorities to respond and solve problems by new solutions, providing creativity and innovative opportunities for students, creating freethinking and self-expressing atmosphere for students, using intellectual properties of students, developing knowledge, skill, and perception through effective interaction between teachers with students, and finally facilitating the software movement and science production in society.

\section{Relationship between Knowledge Management and Team Learning}

Nonaka and Takeuchi (1995) stated that the organizations which have been interested in knowledge management and acquiring knowledge are trying to involve in the process of creating knowledge. This type of knowledge directs the organisation toward development (Hassanian, Ahanchian, Ahmadi, Gholizadeh, and Karimi-Moonaghi, 2015). The knowledge creation is a continuous spiral process of dynamic interactions between tacit and explicit knowledge. Therefore, it is necessary to relate these two types of knowledge to each other. The issues such as perception, intuition, suspicion, unwanted feeling, values, imaginations, metaphor and comparison are considered as the forgotten points in organizations and companies. These organizations believed that knowledge has been created among people by interpersonal interactions. Nonaka and Takeuchi (1995) believed that creating knowledge has always been begun from person and personal knowledge and then changes into valuable organizational knowledge.

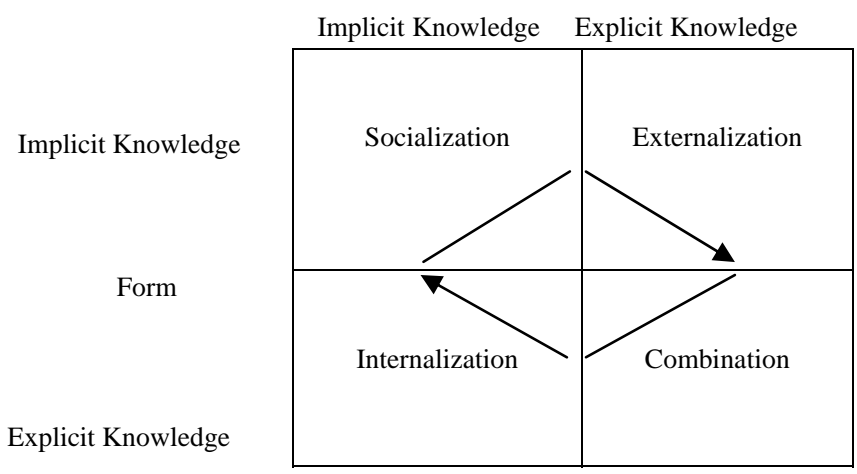


Figure 4. Knowledge management process model of Nonaka and Takeuchi (1995)

According to their view, there are four stages in changing knowledge creation process and producing knowledge through which individual knowledge has transferred to organizations (Soleimani \& Nikooravesh, 2014). Producing knowledge is considered as the social process among people in which changing knowledge is not a unilateral process, but also is an interactive one. Figure 4 presents knowledge management process model in which four processes of producing knowledge are mentioned, namely socialization, combination, externalization, and internalization. Socialization processes focuses on tacit to tacit knowledge linking. It is also known as converting new knowledge through shared experiences and mental models to improve knowledge (Jafari Moghaddam, 2009). This process provides a clear mutual understanding through sharing views, intellectual storm, and professor-student interactions with supporting. Group experience to share knowledge is a useful tool for creating new ideas. Exchanging experiences is a considerable fact during the process of learning and social learning is considered as an important tool to facilitate the process of changing implicit knowledge into the implicit one (Sallis \& Jones, 2002). This issue occurs among effective teams or co-workers with same idea. In this stage, students are able to speak about important issues through discussion meeting, scientific discussion, electronic post, internet, and each others' thoughts. To share knowledge, group experience is a useful tool to generate new ideas and exchange experiences. Moreover, learning process and social learning are considered as important tools to facilitate changing the implicit knowledge into the implicit one. Knowledge transfer by socialization among students occurs through observation, imitation, and practice (Latifian \& Amiri, 2008). Making an effort to socialize seems to provide conditions in class so that the behaviour of students becomes too friendly whenever they share knowledge, experience, and information. Also, the behaviour of teacher is determined through identifying the relationship between students and working methods. Finally, it enables the group to unite and integrate their programs. On the other hand, students have shared and exchanged their information and knowledge through forming teams. It is expected that such behaviours create powerful groups and relations by sharing knowledge between members.

Externalization is a process of articulating tacit knowledge into such explicit knowledge as concepts. This process often uses metaphors, analogies, concepts, and hypothesis or models (Qelichkhani, 2009). In the team atmosphere, metaphors help the members to present their own implicit knowledge and therefore they assist others to use these metaphors as they are used in organizational environments (Sallis \& Jones, 2002). Since, changing implicit knowledge into explicit one is considered as a difficult task, the need for a mediator seems to be urgent in this stage. Knowledge journalist is a person who is able to discuss with other scholars to extract their knowledge. When knowledge is converted from tacit to explicit, it can simply be shared with others and used throughout the organization (Qelichkhani, 2009). In this process, ideas have been transformed into practical reality. Metaphors and allegories are considered as the samples of this process. Writing papers is considered as an example of externalization process in which the purpose is making accessible documents of students, professors, and employees' experiences (Latifian \& Amiri, 2008). In externalizing knowledge, behaviours such as 
exchanging thoughts, ideas, and professional opinions among students, presenting technical definitions to create and use more mutual information networks in order to understand laws, and expressing opinions or clear examples, have been granted. .

Combination process happens when the knowledge is explicit one and its changes easily happen. It refers to the recombination process of discrete components of explicit knowledge. In this stage, new knowledge is formed from new combination of explicit knowledge. In other words, when the existing concepts in a knowledge system have systematic base, combination occurs (Qelichkhani, 2009). The combination process of knowledge provides a basis for sharing and testing ideas. This knowledge forms and changes easily in graphs, research, and technical papers (Latifian \& Amiri, 2008). This knowledge transfer has been done by media or learning in formal environments and lectures, educational workshops, published papers, conferences, and seminars (Sallis \& Jones, 2002). Individual ability of students has formed on the basis of groups' successful activities. The success of projects and approaches depends on different students and different knowledge components. The concept of organizational learning forms base on this reality that group ability cannot explain and solve the problems on the basis of members' individual skills. The potential of solving problem depends on the knowledge base of group members. The collective knowledge is more important than individual knowledge, especially for long-term survival of the groups. Teachers can develop the ways of combining knowledge in groups, the behaviours including discussion among the individuals, recording new events to use them in affairs and doing duties desirably, and acquiring new knowledge through valid sources of information. These patterns of behaviour may cause that the students learn responsible behaviour for their group activities and obtain integrated identity.

The process of internalization takes place through distributing and promoting newly acquired behaviour and newly understood mental models. Internalization has a common theoretical basis practical learning and can change group or individual experiences into the individual mental models (Qelichkhani, 2009). This element helps the teams to draw their mental imaginations about issues needed to be solved and it allows participants to propose their experiences and findings about their desired issues.

Internalizing these ideas has been effective in developing mutual understanding of learning culture in informal educational system of universities (Sallis \& Jones, 2002). When an implicit knowledge has changed into the explicit one, it can form the common mental models or technical knowledge and change it into the valuable property for people, experience groups, and organizations (Soleimani \& Nikooravesh, 2014). Nonaka (1994) believed that innovation does usually occur when there are social interactions. Becoming more sociable allows students to propose their experience of problems which is implicit and then their new useful solutions to overcome them which is explicit. During internalization process, many traditional approaches seem to be effective in process of knowledge exchange including lateral thoughts and learning during working, obligatory communication, and imaginary trip. Students have obtained the specific knowledge based on their mental and their environmental conditions and changes during the internalization (Jafari Moghaddam, 2009).. If teachers act based on their internalized knowledge in their classroom, they will provide conditions for students to discover new innovative ways. Furthermore, if they act in a way that they can find solutions for the probable 
problems, they will comprehend the proposed issues better and consequently they will encourage their friends to learn new knowledge and construct knowledge from their existing concepts. Therefore, the moods and emotions of group members become better, cultural participation forms in them, and the success of group becomes the thought of all members. The concept of knowledge is a necessary tool for more efficient management in organizations, so increasing working knowledge and ability helps to improve groups' dynamics and success (Soleimani \& Nikooravesh, 2014).

\section{Conclusion}

One of the main reasons of teaching is transferring the knowledge to the others. If teaching can be seen as a means of producing knowledge, that production is much narrower than it is for research, as it is related mainly to pedagogical knowledge. Education refers to the link between knowledge production and knowledge use. Teachers only not have to teach student, but also they have to share their knowledge with each other. Effective knowledge transfer has been possible through effective learning. Effective learning has been obtained through active learning, collective and participatory learning, responsibility towards cooperative learning, view exchange, using others' experiences, and obtaining a general understanding. In such kind of environment, people learn sympathy, empathy, responsibility, unity and social cohesion, organizational culture and team life, in additional to accepting special responsibilities as a team member. Therefore, they understand their individual differences, respect others' social right, explain their own perspectives of team and criticize other different views, and finally train social order, cooperation, participation, intrapersonal skills, problem solving skills, and critical thought. Knowledge management has been known as a method to control visible properties of knowledge, especially intangible ones in order to provide an effective atmosphere for creating communication and confidence through face to face visits. It also provide a common base through discussing, team working, conversation, reporting, evaluating performance on the basis of sharing knowledge, and creating.

Educational systems have to create motivation, skills, and abilities to facilitate and increase the process of obtaining knowledge through environment and establish small groups in learning team. Although, knowledge is not considered as a manageable concept, it has been created in a managed environment. Sharing knowledge through encouraging and rewarding becomes possible, because knowledge creates identity and encourages people to spread knowledge unexpectedly. People have needed to exchange the ideas to obtain suitable answer; they have not had the other way than using all their own abilities. Due to the similarity of individual and organizational learning purposes to the common purpose of members, using others' knowledge and skills is an avoidable fact. Undoubtedly, members have sought to manage and use it with the purpose of proposing effective solutions for solving problems.

\section{References}

Ackoff, R. L. (1989). From data to wisdom. Journal of Applied Systems Analysis, 16, 3-9.

Baier, A. (1986). Trust and antitrust ethics. Personnel Review, 25(5), 231-260.

Chan, C. C. A. (2003). Examining the relationships between individual, team, and organizational learning in an Australian hospital. Learning in Health \& Social Care, 2(4), 223-235. 
Chi-Hong, L. (2010). Critical factors of implementing knowledge management in school environment: A qualitative study in Hong Kong. Research Journal of Information Technology, 2, 66-80.

Davenport, T., \& Prusak, L. (1998a). Working knowledge: How organizations manage what they know. Cambridge, MA: Harvard Business School Press.

Davenport, T. H., \& Prusak, L. (1998b). Knowledge management (H. Rahman Seresht, Trans). Tehran: Sapco.

Drucker, P. F. (1984). The new meaning of corporate social responsibility. California Management Review, $26,53-63$.

Fulk, J., Heino, R., Flanagin, A. J., Monge, P. R., \& Bar, F. O. (2004). A test of the individual action model for organizational information commons. Organization Science, 15(5), 569-585.

Garfield, S. (2006). Ten reasons why people do not share their knowledge. KM Review, 9(2), 10-11.

Gomez, E.A., Wu, D., \& Passerini, K. (2010). Computer-supported team based learning: The impact of motivation, enjoyment, and team contributions on learning outcomes. Computers \& Education, 55, 378-390.

Hassanian, Z. M., Ahanchian, M. R., Ahmadi, S., Gholizadeh, R. H., \& Karimi-Moonaghi, H. (2015). Knowledge creation in nursing education. Global Journal of Health Science, 7(2), 44-55.

Hassanzade, M. (2007). Knowledge management: Concepts and substructures. Tehran: Ketabdar Publication.

Hilgard, E. R., \& Marquis, D. G. (1940). Conditioning and learning. New York: Appleton-Century.

Jafari Moghaddam, S. (2009). Documentation of experiences of managers: In opinion of knowledge management $\left(1^{\text {st }}\right.$ ed.). Tehran: Research and Management Training Publication.

Latifian, A., \& Amiri, G. H. (2008). The knowledge management process in informal educational system of universities on the basis of theory of Nonaka and Takeuchi. Paper presented at the First International Conference of Informal Teaching and Learning, Mashhad, Iran.

Lee, J. N., Huynh, M. Q., Chi-Wai, K. R., \& Pi, S. M. (2000). The evolution of outsourcing research: What is the next issue? Paper presented at the Thirty-third Annual Hawaii International Conference, Hawaii, USA.

Michelson, D., Allen, A. J., Busner, J., Casat, C., Dunn, D., Kratochvil, C.,... Harder, D. (2002). Once daily atomoxetine treatment for children and adolescents with attention deficit hyperactivity disorder: A randomized placebo-controlled study. American Journal of Psychiatry, 159(11), 1896-1901.

Mousavi, Z. S., \& Alavi-Basir, N. S. (2014). The role of team learning in attracting intellectual properties and knowledge management. Paper presented at the Third National Conference on Accounting and Management, Tehran, Iran.

Nonaka, I. (1994). A dynamic theory of organizational knowledge creation. Organization Science, 5(1), 14-37.

Nonaka, I., \& Takeuchi, H. (1995). The knowledge creating company: How Japanese companies create the dynamics of innovation. New York: Oxford University Press.

Pashler, H., McDaniel, M., Rohrer, D., \& Bjork, R. (2008). Learning styles: Concepts and evidence. Psychological Science in the Public Interest, 9(3), 106-119.

Parsa, M. (1995). According to psychological learning theories. Tehran: Sokhan.

Qelichkhani, B. (2009). Knowledge management: Creating process, sharing, and using intellectual property in jobs. Tehran: Samt.

Sabin, H., Larson, S., \& Nellen, T. (2000). The PACE model for online teaching and student support. Learning Technology Newsletter, 2(1), 16-20.

Salarzehi, H., Moradzade, A., \& Arab, A. (2012). The role of the components of knowledge management in predicting the components of organizational health (Case study: Roads and urbanization of the southern department of Sistan and Balochestan. Public Management of Zahedan University, 5(18), 85-108.

Sallis, E., \& Jones, G. (2002). Knowledge management in education: Enhancing learning \& Education. London, UK: Kogan Page Ltd.

Senge, P. M. (1990). The leader’s new work: Building learning organizations. Sloan Management Review, 32(1), 7-23.

Senge, P. (2001). The fifth discipline: The art and practice of the learning organization (H. Hedayat \& M. Roshan, Trans.). Tehran: Industrial Management Institute.

Sibley, J., \& Par Melee, D. X. (2008). Knowledge is no longer enough: Enhancing professional education with team-based learning. New Directions for Teaching \&Learning, 116, 41-53.

Sohrabi, B., \& Darmi, H. (2010). Knowledge management with MBA approaches $\left(1^{\text {st }}\right.$ ed.).Tehran: SAMT. 
Soleimani, B., \& Nikooravesh, A. (2014). Management based on health knowledge of organization. Paper presented at the International Conference on Economy, Accounting, Management and Social Science, Poland.

Yaghoubi, M., Karimi, S., Javadi, M., \& Nikbakht, A. (2011). A correlation study on organization learning and knowledge management in staffs in selected hospitals of Isfahan University of Medical Sciences. Journal of Health Administration, 13, 65-75.

Yaghoubi, M., Agharahimi, Z., Daryabeygi, M., \& Javadi, M. (2012). The relationship between application of organizational learning and demographic features of staffs working in pediatrics medical center. Iranian Journal of Medical Education, 11, 1074-1082.

Yousefi, A., \& Gholami, B. (2006). View of female teachers about levels of knowledge management. Journal of Knowledge \& Research in Cultural Sciences, 1(10), 29-46. 